\title{
Significance of Age in Japanese Patients Receiving Sunitinib as First-line Systemic Therapy for Metastatic Renal Cell Carcinoma: Comparative Assessment of Efficacy and Safety between Patients Aged $<75$ and $\geq 75$ Years
}

\author{
HIDEAKI MIYAKE, RYOTA AKI, YUTO MATSUSHITA, KEITA TAMURA, DAISUKE MOTOYAMA, \\ TOSHIKI ITO, TAKAYUKI SUGIYAMA and ATSUSHI OTSUKA
}

Department of Urology, Hamamatsu University School of Medicine, Hamamatsu, Japan

\begin{abstract}
Background/Aim: To date, it has not been well characterized whether sunitinib is effective in elderly patients with metastatic renal cell carcinoma $(m R C C)$. The objective of this study was to investigate the impact of age on clinical outcomes of $m R C C$ patients receiving sunitinib. Patients and Methods: The efficacy and safety of first-line sunitinib in 154 consecutive mRCC patients were retrospectively compared between patients aged $<75$ $(n=125)$ and $\geq 75(n=29)$ years. Results: There were no significant differences in the major clinicopathological characteristics between younger and older patients; however, the reduction of the initial dose of sunitinib was significantly more frequent in older than younger patients. No significant difference in response rate, clinical benefit rate or proportion of patients going on to receive second-line therapy was noted between these two groups. Furthermore, there was no significant difference in progression-free survival (PFS) or overall survival (OS) between the two groups, and no significant impact of age on PFS or OS was documented by the Cox proportional hazards regression analyses. Of several adverse events, only anemia and fatigue were significantly more frequently observed in older than younger patients. Although there was no significant difference in the incidence of dose reduction or discontinuation of sunitinib between the two groups, the interruption of sunitinib was more frequently required in older than younger patients. Conclusion: These findings suggest that advanced age alone should not be regarded as
\end{abstract}

Correspondence to: Hideaki Miyake, Department of Urology, Hamamatsu University School of Medicine, 1-20-1 Handayama, Higashi-Ku, Hamamatsu 431-3192, Japan. Tel: +81 534352306, Fax: +81 534352305, e-mail: hideakimiyake@hotmail.com

Key Words: Metastatic renal cell carcinoma, sunitinib, age, efficacy, safety. a contraindication to the introduction of sunitinib as firstline systemic therapy for $m R C C$ patients.

Older patients are regarded as having increased risks of developing a wide variety of malignant tumors, including renal cell carcinoma (RCC) (1). In fact, RCC is most frequently diagnosed between the ages of 60 and 70 years, and $>25 \%$ of newly diagnosed patients are $>75$ years (2). In general, the prognosis of older cancer patients tends to be poorer due to their characteristics that can have a significant impact on the treatment of these patients. For example, older cancer patients are usually more likely to have a poorer performance status (PS) and a higher incidence of severe comorbidities, resulting in a lower tolerance to several therapeutic modalities compared with younger cancer patients (3). Furthermore, older RCC patients have been shown to exhibit some specific characteristics, such as an increased prevalence of Von Hippel-Lindau mutation as well as clear cell histology $(4,5)$. For older patients with RCC, therefore, it is necessary to consider a therapeutic strategy different from that for younger patients.

In the last decade, several types of molecular-targeted agents were introduced into clinical practice to treat patients with metastatic RCC (mRCC), and the prognosis of mRCC patients has been markedly improved compared to that in the era of cytokine therapy $(6,7)$. Of these agents, sunitinib, an orally available inhibitor of multiple tyrosine kinases, including vascular endothelial growth factor receptors and platelet-derived growth factor receptors, is widely recognized as having one of the most powerful antitumor activities against mRCC through its inhibitory effects on both tumor cell proliferation and angiogenesis (8). In a pivotal randomized clinical trial (RCT), sunitinib was demonstrated to have an efficacy superior to interferon- $\alpha$ as first-line therapy for mRCC, with a median progression-free survival (PFS) of 11 versus 5 months, respectively (9); thus, sunitinib has played a central role in first-line treatment of $\mathrm{mRCC}$ patients. 
To date, RCTs for the evaluation of molecular-targeted agents against mRCC under-represented the actual proportion of older patients relative to the general population of mRCC patients. As for sunitinib, despite the fact that some retrospective studies have analyzed the clinical outcomes in older populations with mRCC (10-13), the actual efficacy and tolerability of this agent in older patients, particularly those in Japanese patients, remain poorly documented. Furthermore, the recent introduction of immune checkpoint inhibitors has resulted in marked changes in the strategy of systemic therapy for mRCC, including first-line therapy (14); however, nivolumab, one of these agents, was previously reported to be less effective in older than younger mRCC patients (15). Considering these findings, this study included a total of 154 consecutive $\mathrm{mRCC}$ patients who were treated with sunitinib as first-line systemic therapy, and the clinical outcomes in these patients were comprehensively compared between patients aged $<75$ and $\geq 75$ years in order to clarify the significance of treatment of older mRCC patients with sunitinib.

\section{Patients and Methods}

Patients. This study was retrospectively performed by reviewing clinicopathological data from a total of 154 consecutive Japanese patients with mRCC who were treated with sunitinib as first-line systemic therapy between January 2010 and June 2017 in a routine clinical setting at our institution. Thirteen patients, who did not undergo radical nephrectomy, received needle biopsies of the primary kidney tumor to determine the histopathological subtype; thus, all 154 were pathologically diagnosed with primary RCC. The design of this study was approved by the Research Ethics Committee of our institution, and the need to obtain informed consent for involvement in this study from all of the included patients was waived due to its retrospective design.

Administration of sunitinib. As a rule, sunitinib was initially administered to all patients based on the standard dosing schedule reported by Motzer et al. (9); that is, they orally received $50 \mathrm{mg}$ of sunitinib once daily in repeated 6-week cycles consisting of 4 weeks on, followed by 2 weeks off. Sunitinib was continuously administered until disease progression occurred or an intolerable adverse event (AE) developed, and the dose could be reduced to $37.5 \mathrm{mg}$ daily, and then further to $25 \mathrm{mg}$ daily according to the severity of $\mathrm{AE}$ in each patient. It was also permitted to modify the starting dose according to patient factors, such as age, body weight and physiological functions of major organs. In addition, after 2014, an alternative dosing schedule with 2 weeks of treatment and 1 week off was introduced based on the preference of the physician without strictly determined criteria (16).

Evaluation. As baseline evaluations at the introduction of sunitinib, the clinicopathological examinations and PS were assessed according to the 7th edition of the UICC TNM classification system and Karnofsky PS scale, respectively, while risk classification was determined using both the Memorial Sloan-Kettering Cancer Center (MSKCC) and International Renal Cell Carcinoma Database
Consortium (IMDC) systems $(17,18)$. Prior to the intial treatment with sunitinib, all of the included patients received radiological examinations involving computed tomography (CT) of the brain, chest and abdomen and/or radionuclide bone scintigraphy. Tumor measurements were generally performed by CT before and every 6 to 12 weeks after the initiation of treatment with sunitinib. Responses and AEs were assessed by each treating physician based on the Response Evaluation Criteria in Solid Tumors v.1.1 and National Cancer Institute Common Terminology Criteria for Adverse Events version 3.0, respectively.

Statistical analysis. Statview 5.0 software (Abacus Concepts, Inc., Berkley, CA, USA) was employed in all statistical analyses, and $p<0.05$ was considered significant. Differences of several factors between the two groups were analyzed by the Chi-squared test. Progression-free survival (PFS) and overall survival (OS) rates were calculated using the Kaplan-Meier method, and differences were evaluated by the log-rank test. The prognostic significance of certain parameters was analyzed using the Cox proportional hazards regression model.

\section{Results}

Characteristics of included patients according to age. Of the 154 included patients, $125(81.2 \%)$ and $29(18.8 \%)$ were $<75$ and $\geq 75$ years old, respectively. Table I presents the major clinicopathological parameters and treatment exposure profiles in the 154 patients according to age. No significant differences in these parameters were noted between younger and older patients. However, despite the lack of a significant difference in the prevalence of different dosing schedules between the two groups, the reduction of the initial dose of sunitinib in older patients was significantly more frequent than that in younger patients.

Oncological outcomes according to age. Table II summarizes the oncological outcomes between younger and older patients. There was no significant difference in the response rate, clinical benefit rate or proportion of patients going on to receive second-line systemic therapy between the two groups. In this series, the median intervals of PFS in younger and older patients were 9.2 and 8.1 months, respectively, while those of OS in younger and older patients were 38.8 and 31.2 months, respectively. As shown in Figure 1, both the PFS and OS in the older patients were similar to those in the younger patients.

The impacts of several clinicopathological factors on the PFS and OS in the 154 patients were then assessed using the Cox proportional hazards regression model (Table III). Univariate analyses identified the following significant prognostic indicators: prior nephrectomy, MSKCC classification, Creactive protein (CRP) level, bone metastasis, liver metastasis and dosing schedule for PFS, and prior nephrectomy, MSKCC classification, IMDC classification, CRP level, lymph node metastasis, bone metastasis and liver metastasis for OS; 
Table I. Patient characteristics and treatment profile.

\begin{tabular}{|c|c|c|c|}
\hline \multirow[b]{2}{*}{ Variables $(\%)$} & \multicolumn{2}{|c|}{ Age (years) } & \multirow[b]{2}{*}{$p$-Value } \\
\hline & $<75(\mathrm{n}=125)$ & $\geq 75(\mathrm{n}=29)$ & \\
\hline Gender & & & 0.55 \\
\hline Male & $89(71.2)$ & $19(65.5)$ & \\
\hline Female & $36(28.8)$ & $10(34.5)$ & \\
\hline Nephrectomy & & & 0.84 \\
\hline Yes & $115(92.0)$ & $27(93.1)$ & \\
\hline No & $10(8.0)$ & $2(6.9)$ & \\
\hline MSKCC risk classification & & & 0.82 \\
\hline Favorable & $32(25.6)$ & $9(31.0)$ & \\
\hline Intermediate & $63(50.4)$ & $14(48.3)$ & \\
\hline Poor & $30(24.0)$ & $6(20.7)$ & \\
\hline IMDC risk classification & & & 0.93 \\
\hline Favorable & $30(24.0)$ & $7(24.1)$ & \\
\hline Intermediate & $65(52.0)$ & $16(55.2)$ & \\
\hline Poor & $30(24.0)$ & $6(20.7)$ & \\
\hline C-reactive protein & & & 0.64 \\
\hline$<0.8 \mathrm{mg} / \mathrm{dl}$ & $76(60.8)$ & $19(65.5)$ & \\
\hline $0.8 \mathrm{mg} / \mathrm{dl} \leq$ & $49(39.2)$ & $10(34.5)$ & \\
\hline \multicolumn{4}{|l|}{ Major metastatic organs } \\
\hline Lung & 87 (69.6) & $22(75.9)$ & 0.5 \\
\hline Lymph node & $34(27.2)$ & $9(31.0)$ & 0.68 \\
\hline Bone & $33(26.4)$ & $8(27.6)$ & 0.9 \\
\hline Liver & $16(12.8)$ & $3(10.3)$ & 0.72 \\
\hline Histology of primary tumor & & & 0.84 \\
\hline Clear cell cancer & $110(88.0)$ & $27(93.1)$ & \\
\hline Non-clear cell cancer & $15(12.0)$ & $2(6.9)$ & \\
\hline Sarcomatoid feature & & & 0.8 \\
\hline Positive & $15(12.0)$ & $3(10.3)$ & \\
\hline Negative & $110(88.0)$ & $26(89.7)$ & \\
\hline Dosing schedule of sunitinib & & & 0.34 \\
\hline Standard & $89(71.2)$ & $18(62.1)$ & \\
\hline Alternative & $36(28.8)$ & $11(37.9)$ & \\
\hline Initial reduction of sunitinib dose & & & $<0.001$ \\
\hline Yes & $24(19.2)$ & $16(55.2)$ & \\
\hline No & $101(80.8)$ & $13(44.8)$ & \\
\hline
\end{tabular}

MSKCC: Memorial Sloan-Kettering Cancer Center; IMDC: International Renal Cell Carcinoma Database Consortium.

however, the age did not have a significant impact on PFS or OS. On multivariate analyses of these significant prognostic indicators, the following factors were shown to be independently associated with the prognosis: CRP level for PFS, and MSKCC classification, CRP level, bone metastasis and liver metastasis for OS.

Profiles of AEs according to age. Table IV shows a comparison of the profiles of commonly observed AEs during and following the use of sunitinib between younger and older patients. The incidences of anemia and fatigue in older patients were significantly higher compared with those in younger patients; however, there were no significant differences in the incidences of the remaining AEs between
Table II. Oncological outcomes following treatment with sunitinib.

\begin{tabular}{|c|c|c|c|}
\hline & \multicolumn{2}{|c|}{ Age (years) } & \multirow[b]{2}{*}{$p$-Value } \\
\hline & $<75(\mathrm{n}=125)$ & $\geq 75(\mathrm{n}=29)$ & \\
\hline Response $(\%)$ & $39(31.2)$ & 8 (27.6) & 0.7 \\
\hline Clinical benefit (\%) & $101(80.8)$ & $23(79.3)$ & 0.86 \\
\hline $\begin{array}{l}\text { Median progression-free } \\
\text { survival (months) }\end{array}$ & 9.2 & 8.1 & 0.47 \\
\hline Median overall survival (months) & 38.8 & 31.2 & 0.56 \\
\hline $\begin{array}{l}\text { No. of patients receiving } \\
\text { second-line therapy }(\%)\end{array}$ & $106(84.8)$ & $23(79.3)$ & 0.47 \\
\hline
\end{tabular}

the two groups. With respect to AEs corresponding to $\geq$ grade 3 , no significant differences in the incidences of any of the AEs were noted between the two groups. Furthermore, despite the lack of significant difference in the incidence of dose reduction or discontinuation of sunitinib between the two groups, the interruption of sunitinib was more frequently required in older than younger patients.

\section{Discussion}

Sunitinib, a powerful inhibitor of multiple tyrosine kinases, has been shown to improve the prognosis of patients with mRCC, and current major guidelines recommend sunitinib as one of the standard agents as firstline therapy for $\mathrm{mRCC}$ with a predominant clear cell histology $(8,9)$. In fact, since the introduction of sunitinib into treatment of mRCC 10 years ago, OS of mRCC patients has more than doubled, at least in part due to this agent $(6,8)$. Despite the excellent antitumor activity of sunitinib, it is well-recognized that the treatment of mRCC patients with this agent results in the relatively frequent development of several AEs, such as fatigue, hypertension, diarrhea and thrombocytopenia (8), which could influence the clinical outcomes of these patients, particularly those with a high burden of comorbidity, like older patients (3). However, although the elderly population represents a consistent portion of all mRCC patients (2), limited data are available with respect to the efficacy as well as safety of sunitinib in older patients with mRCC in both RCTs and routine clinical practices (9-13). In this study, therefore, we compared the clinical outcomes of first-line systemic therapy with sunitinib between $\mathrm{mRCC}$ patients aged $<75$ and $\geq 75$ years.

There is no established definition of the elderly in the field of systemic therapy for malignant disease, and controversy with respect to the age threshold differentiating older from younger patients continues to provoke debate (19). Indeed, the chronological age of some older patients 

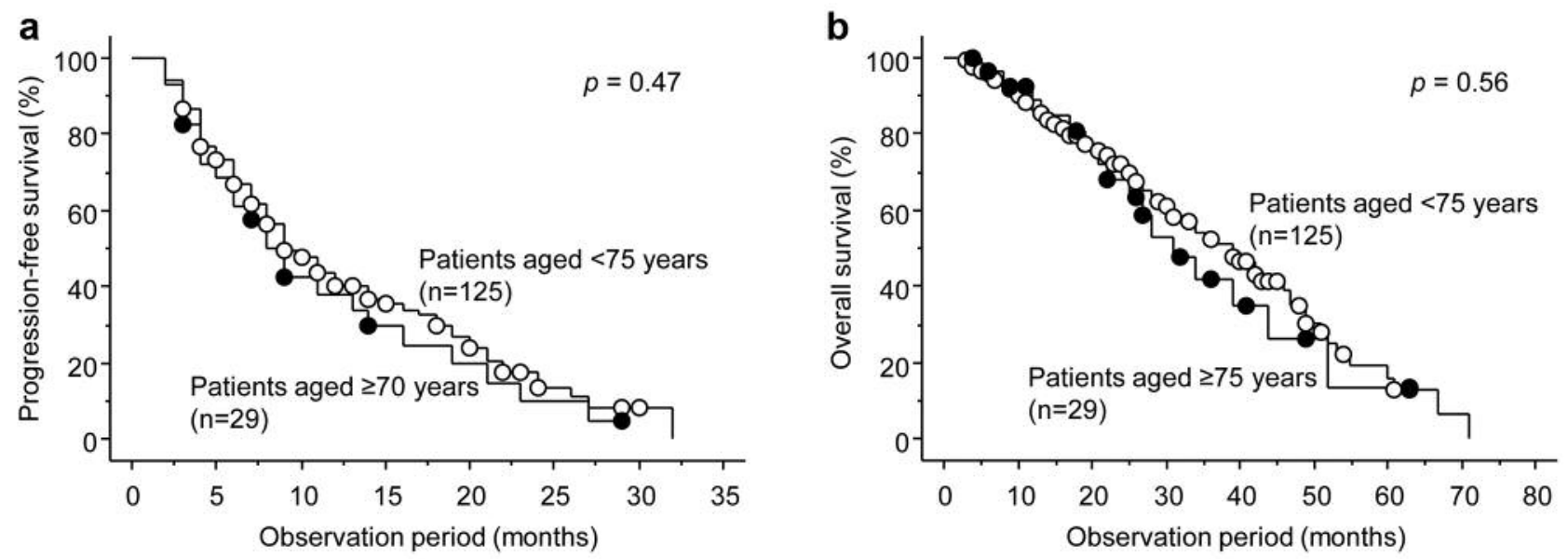

Figure 1. A: Progression-free survival of the 154 patients with metastatic renal cell carcinoma (mRCC) receiving sunitinib as first-line systemic therapy according to age. B: Overall survival of the 154 patients with mRCC receiving sunitinib as first-line systemic therapy according to age.

Table III. Univariate and multivariate analyses of associations between various parameters with progression-free and overall survivals following treatment with sunitinib.

\begin{tabular}{|c|c|c|c|c|c|c|c|c|}
\hline \multirow[b]{3}{*}{ Variables } & \multicolumn{4}{|c|}{ Progression-free survival } & \multicolumn{4}{|c|}{ Overall survival } \\
\hline & \multicolumn{2}{|c|}{ Univariate analysis } & \multicolumn{2}{|c|}{ Multivariate analysis } & \multicolumn{2}{|c|}{ Univariate analysis } & \multicolumn{2}{|c|}{ Multivariate analysis } \\
\hline & Hazard ratio & $p$-Value & Hazard ratio & $p$-Value & Hazard ratio & $p$-Value & Hazard ratio & $p$-Value \\
\hline Age (years) $(<75$ versus $\geq 75)$ & 0.87 & 0.57 & - & - & 0.73 & 0.41 & - & - \\
\hline Gender (male versus female) & 1.12 & 0.58 & - & - & 1.19 & 0.46 & - & - \\
\hline Prior nephrectomy (yes versus no) & 0.31 & 0.037 & 0.47 & 0.16 & 0.29 & 0.018 & 0.58 & 0.15 \\
\hline MSKCC risk classification (poor versus others) & 3.43 & 0.017 & 1.88 & 0.19 & 3.31 & 0.025 & 3.11 & 0.038 \\
\hline IMDC risk classification (poor versus others) & 1.83 & 0.078 & - & - & 2.98 & 0.043 & 1.7 & 0.24 \\
\hline C-reactive protein $(\mathrm{mg} / \mathrm{dl})(<0.8$ versus $\geq 0.8)$ & 0.26 & 0.0068 & 0.28 & 0.027 & 0.21 & 0.0037 & 0.26 & 0.019 \\
\hline Lung metastasis (positive versus negative) & 0.85 & 0.39 & - & - & 0.87 & 0.2 & - & - \\
\hline Lymph node metastasis (positive versus negative) & 1.7 & 0.15 & - & - & 3.02 & 0.04 & 1.73 & 0.22 \\
\hline Bone metastasis (positive versus negative) & 2.83 & 0.043 & 1.83 & 0.28 & 3.25 & 0.038 & 2.71 & 0.043 \\
\hline Liver metastasis (positive versus negative) & 2.98 & 0.0038 & 1.92 & 0.11 & 3.9 & 0.0028 & 3.56 & 0.021 \\
\hline Histological subtype (CCC versus others) & 0.77 & 0.26 & - & - & 0.83 & 0.21 & - & - \\
\hline Sarcomatoid feature (positive versus negative) & 1.87 & 0.1 & - & - & 1.91 & 0.082 & - & - \\
\hline Dosing schedule (standard versus alternative) & 2.34 & 0.045 & 1.72 & 0.34 & 1.94 & 0.077 & - & - \\
\hline Initial dose reduction (yes versus no) & 1.1 & 0.63 & - & - & 1.2 & 0.57 & - & - \\
\hline
\end{tabular}

MSKCC: Memorial Sloan-Kettering Cancer Center; IMDC: International Renal Cell Carcinoma Database Consortium; CCC: clear cell cancer.

could be different from their physiological age, but agerelated physiological changes are likely to occur predominantly between 70 and 75 years. In this study, accordingly, the cutoff point for defining older patients was set at 75 years. To our knowledge, there have been few studies focusing on the impact of age on the utility of sunitinib for mRCC patients, all of which regarded patients $\geq 70$ years as an elderly population; thus, this may be the first study comparing the clinical outcomes of treatment with sunitinib by dividing patients into $<75$ and $\geq 75$ years. In this series, $29(18.8 \%)$ of the 154 included patients were classified into the older group, being consistent with previous studies (10-12), and there were no significant differences in major clinicopathological parameters between younger and older patients in the present study. However, despite the lack of a significant difference in the distribution of different dosing schedules between younger and older patients, the proportion of older patients with a reduction of 
Table IV. Adverse events associated with sunitinib.

\begin{tabular}{|c|c|c|c|c|c|c|}
\hline \multirow[b]{2}{*}{ Adverse events (\%) } & \multicolumn{2}{|c|}{$\begin{array}{l}\text { All grades } \\
\text { Age (years) }\end{array}$} & \multirow[b]{2}{*}{$p$-Value } & \multicolumn{2}{|c|}{$\begin{array}{c}\text { Grade } \leq 3 \\
\text { Age (years) }\end{array}$} & \multirow[b]{2}{*}{$p$-Value } \\
\hline & $<75(\mathrm{n}=125)$ & $\geq 75(\mathrm{n}=29)$ & & $<75(\mathrm{n}=125)$ & $\geq 75(\mathrm{n}=29)$ & \\
\hline Thrombocytopenia & $119(95.2)$ & $28(96.6)$ & 0.75 & $26(20.8)$ & $8(27.6)$ & 0.43 \\
\hline Leukopenia & 97 (77.6) & 26 (89.7) & 0.14 & $11(8.8)$ & $4(13.8)$ & 0.41 \\
\hline Anemia & $74(59.2)$ & $23(79.3)$ & 0.043 & $12(9.6)$ & $4(13.8)$ & 0.5 \\
\hline Hypothyroidism & $76(60.8)$ & $16(55.2)$ & 0.58 & $2(1.6)$ & $1(3.4)$ & 0.52 \\
\hline Diarrhea & $74(59.2)$ & $17(58.6)$ & 0.95 & $3(2.4)$ & $1(3.4)$ & 0.75 \\
\hline Fatigue & $66(52.8)$ & $23(79.3)$ & 0.0092 & $19(15.2)$ & $5(17.2)$ & 0.78 \\
\hline Skin discoloration & $69(55.2)$ & 17 (58.6) & 0.74 & $0(0)$ & $0(0)$ & - \\
\hline Hypertension & $68(54.4)$ & $16(55.2)$ & 0.94 & $8(6.4)$ & $4(13.8)$ & 0.18 \\
\hline Hand-foot syndrome & $65(52.0)$ & $14(48.3)$ & 0.72 & $14(11.2)$ & $2(6.9)$ & 0.49 \\
\hline \multirow[t]{2}{*}{ Liver dysfunction } & $63(50.4)$ & $16(55.2)$ & 0.64 & $0(0)$ & $0(0)$ & - \\
\hline & \multicolumn{2}{|c|}{ Age (years) } & & & & \\
\hline Outcomes $(\%)$ & $<75(\mathrm{n}=125)$ & $\geq 75(\mathrm{n}=29)$ & $p$-Value & & & \\
\hline Dose reduction & $117(93.6)$ & $28(96.6)$ & 0.54 & & & \\
\hline Dose interruption & $69(55.2)$ & $23(79.3)$ & 0.017 & & & \\
\hline Discontinuation of treatment & $26(20.8)$ & $8(27.6)$ & 0.43 & & & \\
\hline
\end{tabular}

the initial dose of sunitinib was significantly larger than that of younger patients. Similarly, De Giorgi et al. reported that $62(33.5 \%)$ of $185 \mathrm{mRCC}$ patients aged $\geq 70$ years treated with sunitinib as first-line therapy underwent a modified regimen whereby the initial dose of sunitinib was reduced, and that patients treated with this modified regimen were older than those treated with the standard regimen (13).

The oncological outcomes, including response rate, clinical benefit rate, proportion of patients further receiving second-line therapy, PFS and OS following the introduction of sunitinib were subsequently compared between mRCC patients aged $<75$ and $\geq 75$ years, and no significant differences in these parameters were documented between the two groups. In addition, an age $\geq 75$ years was not shown to be associated with a poor PFS or OS by the Cox proportional hazards regression analyses. A prognostic trend similar to that in this study for older patients receiving sunitinib was shown in previous studies. For example, Poprach et al. reported that despite the inferior OS of older compared with younger patients, there was no significant difference in the response rate or PFS between the two groups (12), while Hutson et al. conducted pooled analyses of 6 RCTs, and found that both PFS and OS were comparable in younger and older patients who received firstline sunitinib (10). Furthermore, Khambari et al. showed that an age $\geq 75$ years was not associated with an unfavorable OS or short therapeutic duration in $\mathrm{mRCC}$ patients receiving a first-line anti-vascular endothelial growth factor agent, including subitinib, based on data from the IMDC (20). Collectively, these findings suggest that although an appropriately designed RCT is necessary to draw a definitive conclusion on the impact of age on the prognosis of mRCC patients receiving sunitinib, the prognostic significance of age may be weaker in mRCC patients in the era of molecular-targeted therapy.

In routine clinical practice, older cancer patients are likely to have several comorbidities, which could hinder the success of anticancer therapies, including molecular-targeted therapy, and thus warrant special attention to the risk of developing therapy-associated AEs (3). In this study, however, the $\mathrm{AE}$ profile in older patients was shown to be broadly equivalent to that in younger patients, except for the incidence of fatigue and anemia, which were significantly more frequently observed in older than younger patients. Also, in previous studies, the incidences of some AEs in older patients were significantly higher than those in younger patients; however, no differences in the AE profile were reported between younger and older patients treated with sunitinib $(10,12)$. In addition, no significant difference in the incidence of dose reduction or discontinuation of sunitinib was noted between younger and older patients; however, the interruption of sunitinib was more frequently required in older than younger patients. These findings are also consistent with those of previous studies, showing the comparatively high proportion of older patients who needed the interruption of treatment with sunitinib $(11,13)$. 
Here, we would like to emphasize several limitations of this study. Firstly, this was conducted as a retrospective study with a comparatively small number of patients, particularly those $\geq 75$ years. Secondly, this study included only Japanese patients, who have been shown to exhibit profiles on using molecular-targeted agents different from those of Western populations $(21,22)$; therefore, it should be carefully judged whether the findings presented herein can be applied to an overall cohort of patients with mRCC treated with first-line sunitinib. Thirdly, there may be a large number of patients who were excluded from the introduction of first-line sunitinib due to having too many comorbidities and/or a very poor PS, which are evidently common in older populations, resulting in a potential selection bias. Finally, multiple drugs are likely to be administered to older cancer patients owing to high incidences of severe comorbidities (23); thus, some of these drugs may influence the activity of sunitinib.

\section{Conclusion}

To our knowledge, this may be the first study to perform a comparative assessment of clinical outcomes between younger and older $\mathrm{mRCC}$ patients who received sunitinib as first-line systemic therapy employing an elderly-age cutoff point of 75 years, and the findings in this study show that the efficacy as well as tolerability of first-line sunitinib are almost comparable between mRCC patients aged $<75$ and $\geq 75$ years. Accordingly, advanced age alone should not be regarded as a contraindication to the introduction of sunitinib as first-line systemic therapy for an older population with $\mathrm{mRCC}$, even for those aged $\geq 75$ years.

\section{References}

1 Janssen-Heijnen ML, Gondos A, Bray F, Hakulinen T, Brewster $\mathrm{DH}$, Brenner $\mathrm{H}$ and Coebergh JW: Clinical relevance of conditional survival of cancer patients in europe: age-specific analyses of 13 cancers. J Clin Oncol 28: 2520-2528, 2010.

2 Pal SK, Vanderwalde A, Hurria A and Figlin RA: Systemic therapies for metastatic renal cell carcinoma in older adults. Drugs Aging 28: 635-649, 2011.

3 Extermann M: Basic assessment of the older cancer patient. Curr Treat Options Oncol 12: 276-285, 2011.

4 Kondo K, Yao M, Yoshida M, Kishida T, Shuin T, Miura T, Moriyama M, Kobayashi K, Sakai N, Kaneko S, Kawakami S, Baba M, Nakaigawa N, Nagashima Y, Nakatani Y and Hosaka $\mathrm{M}$ : Comprehensive mutational analysis of the VHL gene in sporadic renal cell carcinoma: relationship to clinicopathological parameters. Genes Chromosomes Cancer 34: 58-68, 2002.

5 Gillett MD, Cheville JC, Karnes RJ, Lohse CM, Kwon ED, Leibovich BC, Zincke $\mathrm{H}$ and Blute ML: Comparison of presentation and outcome for patients 18 to 40 and 60 to 70 years old with solid renal masses. J Urol 173: 1893-1896, 2005.
6 Vitale MG and Cartenì G: Clinical management of metastatic kidney cancer: the role of new molecular drugs. Future Oncol 12: 83-93, 2016.

7 Randall JM, Millard F and Kurzrock R: Molecular aberrations, targeted therapy, and renal cell carcinoma: current state-of-theart. Cancer Metastasis Rev 33: 1109-1124, 2014.

8 Motzer RJ, Escudier B, Gannon A and Figlin RA: Sunitinib: Ten years of successful clinical use and study in advanced renal cell carcinoma. Oncologist 22: 41-52, 2017.

9 Motzer RJ, Hutson TE, Tomczak P, Michaelson MD, Bukowski RM, Rixe O, Oudard S, Negrier S, Szczylik C, Kim ST, Chen I, Bycott PW, Baum CM and Figlin RA: Sunitinib versus interferon alfa in metastatic renal-cell carcinoma. N Engl J Med 356: 115-124, 2007.

10 Hutson TE, Bukowski RM, Rini BI, Gore ME, Larkin JM, Figlin RA, Barrios CH, Escudier B, Lin X, Fly K, Martell B, Matczak $\mathrm{E}$ and Motzer RJ: Efficacy and safety of sunitinib in elderly patients with metastatic renal cell carcinoma. Br J Cancer 110: 1125-1132, 2014.

11 Brunello A, Basso U, Sacco C, Sava T, De Vivo R, Camerini A, Barile C, Roma A, Maruzzo M, Falci C and Zagonel V: Safety and activity of sunitinib in elderly patients ( $\geq 70$ years) with metastatic renal cell carcinoma: a multicenter study. Ann Oncol 24: 336-342, 2013.

12 Poprach A, Lakomy R, Bortlicek Z, Melichar B, Pavlik T, Slaby O, Vyzula R, Svoboda M, Kiss I, Studentova H, Zemanova M, Fiala O, Kubackova K, Dusek L, Hornova J and Buchler T: Efficacy of sunitinib in elderly patients with metastatic renal cell carcinoma: data from real-world clinical practice. Drugs Aging 33: 655-663, 2016.

13 De Giorgi U, Scarpi E, Sacco C, Aieta M, Lo Re G, Sava T, Masini C, De Vincenzo F, Baldazzi V, Camerini A, Fornarini G, Burattini L, Rosti G, Ferrari V, Moscetti L, Chiuri VE, Luzi Fedeli S, Amadori D and Basso U: Standard vs adapted sunitinib regimen in elderly patients with metastatic renal cell cancer: results from a large retrospective analysis. Clin Genitourin Cancer 12: 182-189, 2014.

14 Powles T, Albiges L, Staehler M, Bensalah K, Dabestani S, Giles RH, Hofmann F, Hora M, Kuczyk MA, Lam TB, Marconi L, Merseburger AS, Fernández-Pello S, Tahbaz R, Volpe A, Ljungberg B and Bex A: Updated European Association of Urology guidelines recommendations for the treatment of firstline metastatic clear cell renal cancer. Eur Urol, 2017. doi: 10.1016/j.eururo.2017.11.016. [Epub ahead of print]

15 Motzer RJ, Escudier B, McDermott DF, George S, Hammers HJ, Srinivas S, Tykodi SS, Sosman JA, Procopio G, Plimack ER, Castellano D, Choueiri TK, Gurney H, Donskov F, Bono P, Wagstaff J, Gauler TC, Ueda T, Tomita Y, Schutz FA, Kollmannsberger C, Larkin J, Ravaud A, Simon JS, Xu LA, Waxman IM and Sharma P: Nivolumab versus everolimus in advanced renal-cell carcinoma. N Engl J Med 373: 1803-1813, 2015.

16 Miyake H, Harada K, Miyazaki A and Fujisawa M: Improved health-related quality of life of patients with metastatic renal cell carcinoma treated with a 2 -weeks on and 1 week off schedule of sunitinib. Med Oncol 32: 78, 2015.

17 Motzer RJ, Bacik J, Murphy BA, Russo P and Mazumdar M: Interferon-alfa as a comparative treatment for clinical trials of new therapies against advanced renal cell carcinoma. J Clin Oncol 20: 289-296, 2002. 
18 Heng DY, Xie W, Regan MM, Warren MA, Golshayan AR, Sahi C, Eigl BJ, Ruether JD, Cheng T, North S, Venner P, Knox JJ, Chi KN, Kollmannsberger C, McDermott DF, Oh WK, Atkins MB, Bukowski RM, Rini BI and Choueiri TK: Prognostic factors for overall survival in patients with metastatic renal cell carcinoma treated with vascular endothelial growth factortargeted agents: results from a large, multicenter study. J Clin Oncol 27: 5794-5799, 2009.

19 Dutcher JP, Tannir N, Bellmunt J and Escudier B: Experience with sorafenib and the elderly patient. Med Oncol 27: 1359-1370, 2010

20 Khambati HK, Choueiri TK, Kollmannsberger CK, North S, Bjarnason GA, Vaishampayan UN, Wood L, Knox JJ, Tan MH, MacKenzie MJ, Donskov F, Rini BI and Heng DY: Efficacy of targeted therapy for metastatic renal cell carcinoma in the elderly patient population. Clin Genitourin Cancer 12: 354-358, 2014.

21 Miyake H, Miyazaki A, Harada K and Fujisawa M: Assessment of efficacy, safety and quality of life of 110 patients treated with sunitinib as first-line therapy for metastatic renal cell carcinoma: experience in real-world clinical practice in Japan. Med Oncol 31: 978, 2014.
22 Miyake H, Harada KI, Ozono S and Fujisawa M: Assessment of efficacy, safety, and quality of life of 124 patients treated with axitinib as second-line therapy for metastatic renal-cell carcinoma: experience in real-world clinical practice in Japan. Clin Genitourin Cancer 15: 122-128, 2017.

23 Bellmunt $\mathrm{J}$ and Guix $\mathrm{M}$ : The medical management of metastatic renal cell carcinoma: integrating new guidelines and recommendations. BJU Int 103: 572-577, 2009.

Received March 29, 2018

Revised April 29, 2018

Accepted May 2, 2018 